\title{
Research on Evaluation of Building Industrialization Level Based on BIM Technology
}

\author{
Xiaoyu $\mathrm{HE}^{1}$ \\ ${ }^{1}$ Key Laboratory of Building Structure of Anhui Higher Education Institutes, Anhui Xinhua University, Hefei, China
}

\begin{abstract}
This paper analyzes the application value of BIM technology in industrial building projects and the improvement of building industrialization level. Firstly, an evaluation index system of building industrialization level based on BIM technology is established, which consists of 4 first-level indicators and 16 second-level indicators; then, the Analytic Hierarchy Process is used to determine the corresponding weight value of each index; finally, the BIM platform function is used to collect data, and the fuzzy comprehensive evaluation method is used to calculate the evaluation results of the evaluated objects, so as to realize the effective evaluation of the building industrialization level.
\end{abstract}

\section{The introduction}

The construction industry is the pillar industry of China's national economic development, but for a long time, its growth mode has been extensive, serious pollution, low efficiency, high energy consumption and labor intensive. At the same time, with the development of society, the energy conservation and environmental protection of the construction industry also put forward higher requirements, and the cost of labor is getting higher and higher. The extensive growth mode of the construction industry is incompatible with the requirements of energy conservation and environmental protection at the present stage. In the face of these problems in the traditional construction industry, it is urgent to transform the industry, optimize the traditional labor methods and improve labor efficiency through information technology. Therefore, the industrialization of construction has become an inevitable development trend. Up to now, there is still a big gap between the popularization degree of construction industrialization in China and that of developed countries ${ }^{[1]}$. Construction industrialization and building informatization based on BIM technology have become the main development direction of China's current construction industry reform ${ }^{[2][3]}$.

BIM (Building Information Modeling) technology is a data tool applied to project planning, engineering design, construction and operation management. It carries out construction drawing, construction simulation, project quantity statistics and operation management of the Building in the whole life cycle of the project. The core of its application is the integration of information models and the process of information collection, sorting and application ${ }^{[4]}$. Compared with the traditional twodimensional design, BIM has the characteristics of visualization, coordination, simulation, optimization and drawing. These characteristics also provide more convenient strong supports for the evaluation of building industrialization level. According to the application experience of building information model in developed countries such as Europe and America in recent years ${ }^{[5][6]}$, it can be seen that the integration of data by using BIM model can realize the digital expression of project entity and function with features ${ }^{[7]}$.

\section{Establishment of the evaluation index system of building industrialization level based on BIM technology}

\subsection{Constructing idea and principle of index system}

This paper mainly takes the relevant national standards for industrial building evaluation, BIM platform functions and the application of BIM technology in prefabricated buildings as the theoretical basis of the research, and analyzes and extracts relevant indicators through literature reading and research methods.

Building industrialization level evaluation system was established to evaluate objectively the construction level of industrialization of the premise, and the evaluation index system is the most key part of the evaluation system is a scientific and applicable, overall, has the level of systems engineering, and therefore, construct buildings based on BIM technology industrialization level in all aspects of the evaluation index system should be comprehensive consideration factors and should follow the following principles:

(1) Principle of integrity

Building industrialization is a huge system, which involves production mode, industrial chain and external

\footnotetext{
* Corresponding author: hexiaoyu@axhu.edu.cn
} 
environment. The construction of evaluation index system of building industrialization level should cover the whole process of prefabricated building industry from design stage to production and construction stage. At the same time, it should also consider the improvement of information transmission speed, the reduction of workload, the simplification of work difficulty and the improvement of management level, and give full consideration to all aspects involved in construction industrialization. From the perspective of the whole, it should avoid the onesidedness of the index system constructed.

(2) The principle of hierarchy

Construction industrialization is characterized by large scale, complex process and numerous participants. The construction of BIM technology based evaluation index system for the level of construction industrialization needs to have a clear framework structure and hierarchy. It should be based on the hierarchical relationship between different factors, multi-layer progressive, multi-layer division, and clear connections between different levels.

(3) Scientific principles

The evaluation standard system of construction industrialization should have rigor and the number of indicators should be appropriate. If the number of evaluation indicators is too large and the sense of hierarchy is too strong, the evaluation work will be complicated, the data collection will be difficult, the operation will be troublesome, and the key factors affecting the results will be inaccurately controlled. If the evaluation index is too few, it can not meet the requirements of the rigor of the evaluation, and it is easy to ignore some key influencing factors, and the evaluation result deviates from the actual situation of the project. The vocabulary selection of each evaluation index should be as clear, concise and explicit as possible, and the comprehensive evaluation index system should be scientific.

\section{(4) Operability principles}

The index setting of the evaluation system needs to take into account the data collection and calculation process, and each index system should be able to ensure its operability and get sufficient data. The evaluation indexes should be clearly stated, concise and moderate, and the index data should be easy to obtain.

(5) Practical principles

The construction of evaluation index system of building industrialization level based on BIM technology should be based on the development status of prefabricated building industrialization in China and the application of BIM technology, and the index selection should be carried out by combining theory with practice. We must ensure that the selected indicators can directly reflect the current situation of construction industrialization.

\subsection{Index selection}

Construction industrialization needs to start from the whole life cycle of buildings, and give consideration to the efficiency of the whole industrial chain of technology and prefabricated buildings. Therefore, the evaluation of industrialization level should consider the design stage, construction process, management process and comprehensive benefits. This paper integrates these four aspects when selecting indicators.

(1) Design stage

Design phase is the foundation of the whole project, is the beginning of the construction process of industrialization, standardization of design and the application of BIM technology will directly affect the construction of prefabricated, site construction, such as process, only to ensure that the design architecture conforms to the standard, all process to smooth implementation, to achieve full professional work, information management, standardization of prefabricated construction design. The evaluation of architectural design stage mainly includes standardization degree, building assembly rate, integration degree design, design depth and collaborative design.

\section{(2) Construction process}

The construction stage is the realization stage of the project. The construction process is a very important process in the construction project. The management level and construction level are very important, which will directly affect the quality of the prefabricated building. Industrialized building mechanical work degree is higher, building high quality, less impact on the environment, and short construction period, the industrialization level of influence is bigger, it contains six indexes: production and quality control, transportation management, construction management, construction technology, construction quality, degree of integration of decoration.

(3) Management process

The management process runs through the whole life cycle of the construction project. Industrialization is not only the process of the construction industry from design, production to construction, but also the information transmission between various stages. Information management is a necessary means to realize the progress of construction industrialization. BIM technology makes the construction engineering information threedimensional, and can carry the information data of design, production, construction, and operation management, which effectively improves the information level of the project. This paper divides the management process into two main indexes: the application of information technology and the degree of information management.

(4) Comprehensive benefits

Comprehensive benefits are a manifestation of a project in many aspects. A large amount of resources will be consumed in the process of construction. Industrial buildings can reduce the construction, use and maintenance costs of the project, and also have advantages in environmental protection, which can save resources, reduce dust pollution and noise pollution, and reduce environmental damage. The comprehensive benefits are mainly divided into economic benefits (project cost), ecological benefits (environmental protection) and social benefits (social influence).

According to the above analysis, the evaluation index system of building industrialization level based on BIM technology is integrated from the design stage, the construction stage and the management stage as the main 
directions. The specific level system is shown in Table 1.

Table 1. Evaluation index system of building industrialization level based on BIM technology

\begin{tabular}{|c|c|c|}
\hline The target layer & Rule layer & Index layer \\
\hline \multirow{16}{*}{$\begin{array}{l}\text { Evaluation of } \\
\text { Building } \\
\text { Industrialization } \\
\text { Level Based on } \\
\text { BIM Technology }\end{array}$} & \multirow{5}{*}{$\begin{array}{l}\text { The design } \\
\text { phase }\end{array}$} & $\begin{array}{c}\text { Degree of } \\
\text { standardization }\end{array}$ \\
\hline & & $\begin{array}{l}\text { Building assembly } \\
\text { rate }\end{array}$ \\
\hline & & Integrative design \\
\hline & & $\begin{array}{c}\text { The depth of the } \\
\text { design }\end{array}$ \\
\hline & & Collaborative design \\
\hline & \multirow{6}{*}{$\begin{array}{l}\text { Building } \\
\text { process }\end{array}$} & $\begin{array}{l}\text { Production and } \\
\text { quality control }\end{array}$ \\
\hline & & $\begin{array}{c}\text { Transportation } \\
\text { management }\end{array}$ \\
\hline & & $\begin{array}{c}\text { Construction } \\
\text { organization and } \\
\text { management }\end{array}$ \\
\hline & & $\begin{array}{c}\text { Construction } \\
\text { technology }\end{array}$ \\
\hline & & Construction quality \\
\hline & & $\begin{array}{c}\text { Integrated } \\
\text { decoration degree }\end{array}$ \\
\hline & \multirow{2}{*}{$\begin{array}{l}\text { Management } \\
\text { process }\end{array}$} & $\begin{array}{l}\text { Application of } \\
\text { Information } \\
\text { Technology }\end{array}$ \\
\hline & & $\begin{array}{c}\text { Information } \\
\text { management degree }\end{array}$ \\
\hline & \multirow{3}{*}{$\begin{array}{l}\text { Comprehensive } \\
\text { benefits }\end{array}$} & $\begin{array}{c}\text { Economic benefit } \\
\text { (project cost) }\end{array}$ \\
\hline & & $\begin{array}{l}\text { Ecological Benefits } \\
\text { (Environmental } \\
\text { Protection) }\end{array}$ \\
\hline & & $\begin{array}{l}\text { Social Benefits } \\
\text { (Social Impact) }\end{array}$ \\
\hline
\end{tabular}

\section{Determine the index weight of building industrialization level evaluation}

The text adopts the Analytic Hierarchy Process to determine the weight of indicators. Analytic Hierarchy Process is a systematic analysis method combining qualitative analysis and quantitative analysis, which can achieve quantification of subjective thinking and judgment. Its basic principle is the evaluation of relevant elements into goals, principles, index level, such as building a clear hierarchical structure model, and then introduced "1-9 scale", by means of pairwise comparison between various elements, constructing judgment matrix, and then one by one to solve the weight vector of judgment matrix, finally hierarchy total sorts, calculate the comprehensive evaluation index weight vector. The steps of analytic hierarchy process are as follows:

(1) Establishment of hierarchical structure model

The factors related to the problem are divided into layers, each layer affecting the upper layer and the lower layer as well.

(2) Construction of judgment matrix

Starting from the second layer of the model, for the factors of the same layer that are subordinate to (or influence) each factor of the upper layer, according to the
1-9 comparison scale shown in Table 2, the comparison matrix is constructed by pairwise comparison method for each layer.

Table 2. 1-9 comparative scale

\begin{tabular}{|c|c|}
\hline Factors to compare & Quantitative values \\
\hline equal importance & 1 \\
\hline A little important & 3 \\
\hline Highly important & 9 \\
\hline Extremely important & $2,4,6,8$ \\
\hline $\begin{array}{c}\text { The middle value of two } \\
\text { adjacent judgments }\end{array}$ & \\
\hline
\end{tabular}

(3) Calculate the relative weight and do consistency test

For the constructed judgment matrix, the eigenvector corresponding to its maximum eigenvalue is calculated and normalized as the weight vector. In this paper, the summation method is used to approximate the weight vector. The formula is as follows:

$$
\mathrm{w}_{\mathrm{i}}=\frac{1}{\mathrm{n}} \sum_{\mathrm{j}=1}^{\mathrm{n}} \frac{\alpha_{\mathrm{ij}}}{\sum_{\mathrm{k}=1}^{\mathrm{n}} \alpha_{\mathrm{kj}}}, \quad \mathrm{i}=1,2 \cdots, \mathrm{n}
$$

Among them, $\mathrm{W}_{\mathrm{i}^{--}}$The weight vector;

$\alpha_{i j}{ }^{--}$Elements of the judgment matrix;

n--Number of elements.

In general, the consistency test of each comparison matrix should be carried out. If the test fails, the comparison matrix should be reconstructed.

(4) Calculate the total weight of each index

The calculation of the total weight of each index is also called the hierarchical total sorting, that is, the bottom-up layer by layer synthesis, using the correlation matrix table and the weighted sum method to calculate the total weight of each level of indicators relative to the highest level.

\section{Determine the evaluation result of building industrialization level}

Since the industrialization level of building based on BIM technology is affected by a variety of influencing factors, it is difficult to give scientific judgment results by general subjective scoring method and grade evaluation method, and comprehensive evaluation method is needed. In this paper, the fuzzy comprehensive evaluation method is chosen after comparing several methods and referring to relevant references. The specific evaluation process is as follows:

(1) Determine the factor set of evaluation indexes

Suppose there are $\mathrm{N}$ evaluation indicators, then the factor set $X=\left(X_{1}, X_{2}, \cdots X_{n}\right)$

(2) Determine the comment set

Suppose $A=\left(W_{1}, W_{2}, \cdots W_{n}\right)$, each grade can correspond to a fuzzy subset, and $n$ is the number of total evaluation results. Comments can be graded on a 3-5 scale as needed.

(3) Establish fuzzy relation matrix

After the evaluation set is determined, the evaluation indexes should be evaluated from each factor $X_{i}(i=1,2 \ldots$ n) on quantitative, that is, determine from single factor evaluated objects of class membership degree of fuzzy subsets $\left(\mathrm{R} \mid \mathrm{X}_{\mathrm{i}}\right)$, fuzzy relationship matrix is obtained: 


$$
\mathrm{R}=\left[\begin{array}{c}
\left(R \mid X_{1}\right) \\
(R \mid X 2) \\
\cdots \\
(R \mid X n)
\end{array}\right]=\left(\begin{array}{ccc}
\mathrm{r}_{11} & \cdots & \mathrm{r}_{1 \mathrm{~m}} \\
\vdots & \ddots & \vdots \\
\mathrm{r}_{\mathrm{n} 1} & \cdots & \mathrm{r}_{\mathrm{nm}}
\end{array}\right)
$$

Among them, the element in row $\mathrm{i}$ and column $\mathrm{j}$ represents the membership degree of an evaluated object $\mathrm{X}_{\mathrm{i}}$ to the evaluation grade $\mathrm{W}_{\mathrm{j}}$ from the perspective of factors.

(4) Determine the weights of evaluation factors vector Analytic Hierarchy Process (AHP) was used to determine the order of relative importance among evaluation indexes, and then the weight vectors of evaluation factors $U=\left(U_{1}, U_{2}, \cdots U_{n}\right)$ were determined.

(5) Synthesize the result vector of fuzzy comprehensive evaluation

The fuzzy comprehensive evaluation result vector $B$ of each evaluated object is obtained by combining $U$ with $R$ of each evaluated object, that is:

$$
\mathrm{U} \oint \mathrm{R}=\left(\mathrm{U}_{1}, \mathrm{U}_{2}, \cdots \mathrm{U}_{\mathrm{n}}\right)\left(\begin{array}{ccc}
\mathrm{r}_{11} & \cdots & \mathrm{r}_{1 \mathrm{~m}} \\
\vdots & \ddots & \vdots \\
r_{\mathrm{n} 1} & \cdots & \mathrm{r}_{\mathrm{nm}}
\end{array}\right)=\left(\mathrm{b}_{1}, \mathrm{~b}_{2}, \cdots \mathrm{b}_{\mathrm{m}}\right)=\mathrm{B}
$$

$B_{i}$ represents the subordinate degree of the evaluated object to the evaluation level $\mathrm{W}_{\mathrm{j}}$ as a whole. The evaluation with the highest degree of membership is the evaluation result of the object.

\section{Conclusion}

The evaluation of building industrialization level is an evaluation involving the whole life cycle of a building. In this paper, the application value of BIM technology in industrial building projects and the improvement of building industrialization level are combined and analyzed by summarizing relevant literature and investigating actual projects. Firstly, the evaluation index of building industrialization level based on BIM technology is constructed. The selection of indicators follows the principles of integrity, hierarchy, science, operability and practicability, and an index system composed of 4 firstlevel indicators and 16 second-level indicators is established. Then, the Analytic Hierarchy Process is used to determine the corresponding weight value of each index. Finally, the BIM platform function is used to collect data, and the fuzzy comprehensive evaluation method is used to calculate the evaluation results of the evaluated objects. This paper makes use of the advantages of BIM technology to collect data. It can be seen from the research results that it can effectively evaluate the level of building industrialization.

\section{Acknowledgement:}

This research was financially supported by Key Laboratory of Building Structure of Anhui Higher Education Institutes, Anhui Xinhua University (KLBSZD201902)

\section{References}

1. Yang J Y, Liu M X, The development and evolution of prefabricated building in China [J]. Housing industry, 2016 (8) : 14-21.

2. Chen Z G, Focus on "Several Opinions on Further Strengthening Urban Planning and Construction Management" -- Strengthen Urban Planning and Construction Management to Create a New Situation of Urban Modernization Construction[J]. Standardization of engineering construction, 2016 (5) : 18-22.

3. Wang Z X, Zhang R Y, A brief introduction to the research contents of the 13th five-year project on the key technologies of industrial building inspection and evaluation[J]. The quality of the project, 2016, 34 (9) : 107-108.

4. Li T T, Wu X, Yi 1,etc. Research on the application of BIM technology in engineering construction projects[J]. Information technology of civil construction engineering, 2014,6(1):92-95.

5. Borjeghaleh $\mathrm{R}$ M,Sardroud J M.Approaching Industrialization of Buildings and Integrated Construction Using Building Information Modeling[J]. Procedia Engineering, 2016,164:534541 .

6. Zhang J, Long Y,Lv S, et al.BIM-enabled Modular and Industrialized Construction in China[J]. Procedia Engineering,2016,145:1456-1461.

7. Ma Z L, Zhang D D, Ma J K, IPD collaborative work model and information utilization framework based on BIM[J]. Journal of Tongji University (Natural Science Edition), 2014, 42(9):1325-1332. 